$\underline{\xi}=$ 잘

\title{
Effectiveness of a herbal mouthrinse on de novo plaque formation
}

\author{
Jippy R.S. ${ }^{1 *}$, Ananda S.R. ${ }^{2}$, Jithesh Jain ${ }^{3}$ \\ ${ }^{1}$ Post Graduate student, Department of Public Health Dentistry, Coorg Institute of Dental Sciences, Virajpet, Karnataka-571218, India \\ ${ }^{2}$ Reader, Department of Public Health Dentistry, Coorg Institute of Dental Sciences, Virajpet, Karnataka - 571218, India \\ ${ }^{3}$ Professor and Head, Department of Public Health Dentistry, Coorg Institute of Dental Sciences, Virajpet, Karnataka - 571218, India \\ *Corresponding author E-mail:drjippymdsphd@gmail.com
}

\begin{abstract}
Background: Herbal mouthrinses have been recently introduced with the objective of achieving effective plaque control. Till date, chlorhexidine has been a gold standard with regard to anti-plaque agents.

Objectives: To compare the effeciveness of the herbal mouthrinse (Hiora) against chlorhexidine mouthrinse.

Methods:The study is a randomized, double blind, crossover clinical study. At the baseline, the volunteers brush their teeth using toothpaste without any active ingredient for 2 minutes. Oral prophylaxis was performed to ensure that the teeth are free of plaque, stains and calculus. Each subject was randomly assigned to both the experimental groups. During the trials, the volunteers were rinsed their mouths, according to the assigned random sequence of treatments: Chlorhexidine as chemical and HiOra as herbal mouthrinse. Both the mouthrinses were packed in similar coloured bottles but labeled differently and randomly administered to the subjects by a blinded operator. Each subject received oral and written instructions on the use of mouth rinses. After one week, the study subjects were asked to suspend their oral hygiene for 24 hours, and accumulated plaque was re-evaluated with erythrosine. The plaque index was recorded in the six selected teeth at the end of the trial. After the trial period, the usual oral hygiene habits resumed.

Results: There were no statistically significant differences between herbal and chemical mouthrinses.
\end{abstract}

Conclusion: Herbal mouth rinses may be as effective as chlorhexidine as chemical anti-plaque agents with fewer side effects.

Keywords:Chlorhexidine; Chemical; Plaque Control; Ayurvedic; Mouthwash

\section{Introduction}

History of medicine is a fascinating subject as it is a saga of man's struggle against disease. As the civilization advances and as the pattern of disease changes, the medical science also changes (Narayanaswami V 1981 p.1). Sprouted in the pristine land of India, some 5000 years ago, Ayurveda, the science of life and longevity, is the oldest healthcare system in the world and it combines the profound thoughts of medicine and philosophy. Since then Ayurveda has stood for the wholesome physical, mental and spiritual growth of humanity around the world. Today, it's a unique, indispensable branch of medicine, a complete naturalistic system that depends on the diagnosis of human body to achieve the right balance.

Dental plaque is a biofilm that forms naturally on the surfaces of exposed teeth (Marsh PD et al 1995 p.169). It is a complex organized microbial community which has been the primary etiological factor for the most frequently occurring oral diseases, such as dental caries and periodontal diseases. Although the dental biofilm cannot be eliminated, it can be controlled with comprehensive mechanical and oral hygiene practices. Routine tooth brushing is widely recognized as the first step to mitigate the effects of dental plaque and maintain oral health (Axelsson P 1993 p.219).

Several products for chemical inhibition of microbial plaque are available in the dental market. However, certain patients may not be willing or able to perform adequate mechanical plaque removal on a regular basis. These patients could benefit from chemotherapeutic anti-plaque agents as adjuncts to mechanical removal. Topical antimicrobials in dental products have four general mechanisms of action. They can decrease the rate of new plaque accumulation, decrease or remove existing plaque, suppress the growth of pathogenic microflora or inhibit the production of virulence factors (Marsh PD 1992 p.1431).Compounds derived from bisbiguanide including chlorhexidinedigluconate (CHX) and alexidina are the most effective agents currently used (Baker PJ et al 1987 p.1099).Today, therapeutic ingredients available in mouthrinses include various metal ions such as stannous, zinc, copper and also essential oil mixtures, chlorhexidine (CHX) and cetylpyridinium chloride (CPC) (Adams D et al 1994 p.291, Moran JM et al 2000 p.109, Baehni PC et al 2003 p.23).

Mouth rinses that contain essential oils effectively decrease the total number of microorganisms, such as S. mutans (Scheie AA 1989 p.1609, White DJ et al 2008 p.189, Fine DH et al 2007 p.652).Considerable clinical trial evidence is available to show that oral hygiene is significantly improved when a mouth rinse containing essential oils, e.g., Listerine ${ }^{\circledR}$ (Johnson and Johnson, McNEIL-PPC, Inc., Skillman, NJ), which contains alcohol or another option as Mouthwash Concentrate ${ }^{\circledR}$ (One Drop Only $\mathrm{GmbH}$, Stieffring, 14, 13627 Berlin - Germany) which is an alcohol free mouthrinse. The clinical benefits of such mouth rinses are attributable to their bactericidal properties, which prevent or reduce supragingival plaque and gingivitis and decrease intrinsic malodour (Balenseifen JW et al 1970 p. 320). 
Chlorhexidine (CHX) containing mouth rinses are accepted as the gold standard and are used as a positive control in most trials (Kocak MM et al 2009 p.57, Wigger-Alberti W et al 2010).However, these rinses have side effects, such as enamel discoloration, mucosal erosion, taste disturbance, mouth burning, dry mouth, carcinogenic effects and the smoothing of composite materials, which limits their usage to approximately 5 weeks (Moran J et al 1994 p.904). To prevent these side effects, alcohol-free CHX mouth rinses have been developed, one of them is Ondrohexidine ${ }^{\circledR}$ (One Drop Only GmbH, Stieffring, 14, 13627 Berlin-Germany), which is an alcohol free mouthrinse.

The search for alternative products has led to the evolution of natural phytochemicals isolated from plants which have been used in traditional medicine and are considered as good alternatives to synthetic chemicals. Medicinal plants have been used as traditional treatments for numerous human diseases for thousands of years and in many parts of the world. In rural areas of the developing countries, they continue to be used as the primary source of medicine (H. R. Chitme et al 2003 p.70).

Hiora*, A herbal mouthwash known for its antiseptic, antimicrobial, antiplaque and analgesic property (Narayan A 2012 et al p.460). Hiora contains herbs having antimicrobial properties such as oil of syzygiumaromaticum, cinnamomumzeylanicum, and extract of spinaciaoleracea, triphala, trikatu and powders of yashadabhasma and suryakshara. Syzygiumaromaticum which has shown to have antifungal, antiviral, analgesic/anaesthetic, antiseptic, anticoagulant and antioxidant properties.

Several antiplaque agents are being available in the market. However, due to several undesirable side effects associated with these agents stimulated the search for alternate agents (Jagdish L et al 2009 p.30).Hence the purpose of this study is to compare the effect of herbal and chemical mouthrinses on de novo plaque formation.

Hence the aim of this double blinded, randomized controlled study is to assess and compare the effectiveness of the herbal mouthrinse (Hiora) against chlorhexidine mouthwash.

\section{Materials and methods}

This study was designed to compare the effectiveness of the herbal mouthrinse (Hiora) against chlorhexidine mouthwash.

Ethical clearance was obtained from the Institutional Review Board of Coorg Institute of Dental Sciences, Virajpet.

A total of 30 subjects were invited to participate voluntarily in the project and Consent was taken from all the participants by explaining about the study, objectives, reasons, duration and possible risks of the study procedures. The study population comprised dental students, which is an interesting group for this kind of study, taking into consideration that they can be easily controlled in terms of compliance.

Subjects were randomly assigned to the test (HiOra mouthrinse) and control (Chlorhexidine) group.At the baseline - the volunteers brushed their teeth using toothpaste without any active ingredient for 2 minutes. Oral prophylaxis was performed to ensure that the teeth were free of plaque, stains and calculus. During the trials, the test group was given the herbal mouthrinse (Hiora) and the control group was given Chlorhexidine.

All subjects were instructed to use their allocated products $15 \mathrm{ml}$ per 3 minutes twice a day for a week. All participants were instructed to refrain from using any other oral hygiene measures.

Both the mouthrinses were packed in similar coloured bottles, but labelled differently and randomly administered to the subjects by a blinded operator. The subjects were also unaware of which mouthrinse they are being administered.

After one week, the subjects returned to the clinic for the clinical assessments. The day prior to the final assessment, oral hygiene was suspended for 24 hours, and the accumulated plaque was revealed with erythrosine. All measurements were conducted under the same conditions by a qualified, experienced examiner who had participated in similar studies. Plaque was assessed using the modified Quigley \& Hein Plaque Index.

Inclusion criteria:

1) People who are older than 18 years.

2) Systemically healthy and having at least 24 teeth.

Exclusion criteria:

1) Orthodontic appliances or removable prosthesis.

2) Allergies to erythrosine or chlorhexidine.

3) Use of other drugs that might affect normal gingival health.

Data analysis included descriptive statistics such as frequency distribution and cross tabulation. Descriptive statistics was computed and Data analysis was done using the unpaired t- test at a significance level of $5 \%(\mathrm{p}<0.05)$. The data was analysed by using SPSS version 17.

\section{Results}

Of the 30 subjects ( 9 females, 21 males aged 20-25 years) who started, all of them completed the study and were deemed evaluable for analyses. Mean Age of the study subjects was $22.4 \pm 0.92$.

Table 1 and Graph 1 shows the mean PI values for the two mouth rinses used. There were no significant differences $(p>0.05)$ found between HiOra mouthrinse and Chlorhexidine.

Table 1: Plaque Index after $24 \mathrm{Hrs}$ according to the Mouthrinses tested

\begin{tabular}{lll} 
Mouthrinses & Mean PI & Standard Deviation \\
\hline CHX & 2.09 & 0.16 \\
HiOra & 2.15 & 0.14 \\
\hline
\end{tabular}

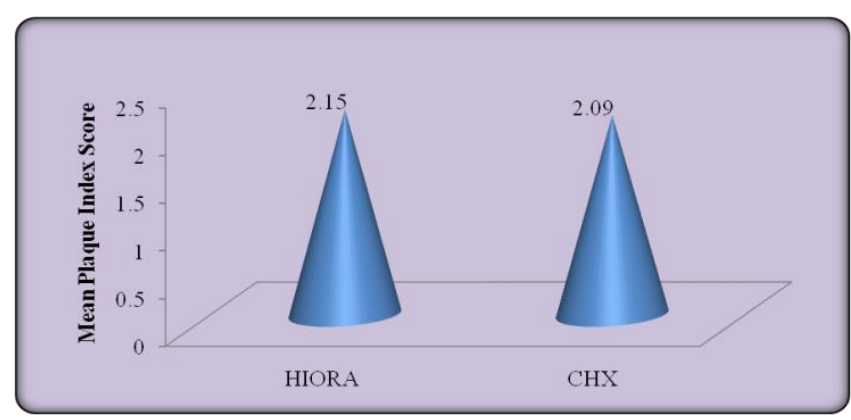

Fig. 1: Mean Plaque Index after $24 \mathrm{Hrs}$ according to the Mouthrinses tested.

\section{Discussion}

This clinical study aimed to compare the inhibition of plaque formation by a Chlorhexidine mouthrinse with that by mouthrinses containing herbal contents. The experimental protocol consisting of no oral hygiene for one day has been used previously because plaque formation can be measured in a short period without causing detectable harm to the study subjects (Rivera S et al 2006 p.163, Claydon $\mathrm{N}$ et al 1995 p.540).

Dental plaque was one of the ecosystems in which maximum number of microorganism were first observed. Dental plaque refers to the aggregates of bacterial cell embedded in a polysaccharide and protein matrix which adheres to the teeth(Sherp HW 1971 p.1199)

Mechanical measures such as tooth brushing and other home devices are the most commonly used methods to clean the teeth. However, it has been revealed that the vast majority of patients will not always completely remove all the plaque by these ways(Glavind L 1977 p.100).

Furthermore, for handicapped or elder individuals use of mechanical methods is more problematic due to their compromised dexterity or motivation(Laher A et al 1996 p.343). To overcome those shortcomings chemical plaque control has been a subject of scientific interest. Antimicrobial rinses have been considered safe in 
reducing plaque and gingivitis(Heasman PA et al 1995 p.323). Chlorhexidine (CHX) is the most common and extensively studied chemical agent for plaque control to date(Kocak MM et al 2009 p.57, Wigger-Alberti $\mathrm{W}$ et al 2010). Its efficacy as a mouthrinse and as a local drug delivery agent to inhibit dental plaque and gingivitis has been well documented (Van Strydonck DA et al 2012 p.1042, RupaliKalsi et al 2011 p.304). It is considered the gold standard of chemical anti-plaque agents against which the efficacy of other antimicrobial and antiplaque agents is assessedmainly because of its broad spectrum of activity against most of the oral pathogens (Fardal O et al 1986 p.863). In spite of potent antiplaque and antimicrobial properties of Chlorhexidine, its widespread and prolonged use is limited by its local side effects.

Chlorhexidine mouth rinses are the gold standard for the inhibition of plaque formation; however, most of these effective formulations have high alcohol content, and they are, consequently, inappropriate for some patients (White DJ et al 2008 p.189, Kocak MM et al 2009 p.57, Wigger, Alberti W et al 2010, Moran J et al 1994 p.904). High amounts of alcohol and CHX are generally associated with side-effects(Moran J et al 1994 p.904). As clinicians, we would prefer to recommend mouth rinses that do not have these side effects. Therefore, there is a need to find alternative, alcohol-free solutions for certain patients and those who do not wish to use alcohol-containing mouth rinses, such as former alcoholics or those whose religions prevent the consumption of alcohol.

The other adverse effects of chlorhexidine include extrinsic staining of teeth, transient impairment of taste sensation and taste perturbation(Lang NP et al 1988 p.43). Occasionally reported are cases of burning sensation and painful desquamation on oral mucosa. In view of this, herbal products are steadily gaining interest in the present era as they are naturally occurring, hence economical. They also claim to have little or no side effects(Kaim JM et a 1998 p.46).

Natural herbs like triphala, tulsipatra, jeshthamadh, neem, cloveoil, ajwain and many more used either alone or combination have been scientifically proven to be safe and effective medicine against various oral health problems like bleeding gums, halitosis, mouth ulcers and decay. The major strength of these natural herbs is that their use has not been reported with any side effect till date(RanjanMalhotra et al 2011 p.349).

HiOra has herbal contents which act on the oral cavity and have protective antimicrobial activities. It contains oil of syzygiumaromaticum, cinnamomumzeylanicum and extract of spinaciaoleracea, triphala, trikatu and powders of yashadabhasma and suryakshara.

The clinical and microbiologic effects of both the mouthrinses being comparable, leaves only one area where the comparison between the two could be possibly relevant. It has been reported that long term use of chlorhexidine is limited by staining of teeth and taste alteration ${ }^{15}$. However; no such effect has been reported with herbal extracts.

Chlorhexidine mouthrinse has been compared with different herbal mouthwashes for their antiplaque and antibiotic properties(Masoumeh K et al 2012 p.18, Singh A et al 2012). The result in this study indicates that the herbal mouthrinse have similar efficacy in relation to chlorhexidine in preventing the plaque formation as shown in Table 1.

Chlorhexidine (mean PI= $2.09 \pm 0.16)$ inhibited plaque growth significantly more than the herbal mouthrinse (mean PI= $2.15 \pm$ $0.14, \mathrm{P}<0.001)$. This result is in accordance with the studies done by Singh A et al (2012) and Malhotra R et al (2014).

The anti-plaque effect of the high bio-available, alcohol-free herbal mouthrinse in this study demonstrates that it is not different from chemical mouthrinse with chlorhexidine. It is suited for a broad range of patients, particularly those sensitive to products containing alcohol and those allergic. It has substantial future implications that these ayurvedic mouthrinses can be promoted by dentist as they have equal plaque reduction efficacy as compared to chlorhexidine with lesser or no side effects.

\section{Conclusion}

This preliminary study proves that Herbal mouthrinses are as effective as chlorhexidine in plaque inhibition. So these ayurvedic preparations can be used in regular dental practice for prevention of plaque formation.Evidence in dental literature support and recognize chlorhexidine as gold standard against which other antiplaque agents are measured. But the long term use of chlorhexidine is limited by its side effects. Herbal products though negate these effects and can be used safely for a longer time period, still need to establish the property of substantivity in order to reach the gold standard of chlorhexidine.

\section{Footnotes}

Source of Support: Nil.

Conflict of Interest: None declare

\section{References}

[1] Narayanaswami V. Origin and development of ayurveda: (a brief history). Ancient Science of Life. 1981; Jul; 1(1):1-7.

[2] Marsh PD, Bradshaw DJ. Dental plaque as a biofilm. Journal of Industrial Microbiology 1995; 15: 169-175. https://doi.org/10.1007/BF01569822.

[3] Axelsson P. Mechanical plaque control. In: Lang NP, Karring T, eds. Proceedings of the 1st European Workshop on Periodontology. Chicago, Quintessence, 1993, 1: 219-243.

[4] Marsh PD. Microbiological aspects of the chemical control of plaque and gingivitis. Journal of Dental Research 1992; 71: 14311438. https://doi.org/10.1177/00220345920710071501.

[5] Baker PJ, Coburn RA, Genco RJ, Evans RT. Structural determinants of activity of chlorhexidine and alkyl bisbiguanides against the human oral flora. Journal of Dental Research 1987; 66:1099106.https://doi.org/10.1177/00220345870660060301.

[6] Adams D, Addy M. Mouthrinses. Advances in Dental Research 1994; 8: 291-301.https://doi.org/10.1177/08959374940080022401.

[7] Moran JM. Chemical plaque control - prevention for the masses. Periodontology 2000 1997; 15: 109-117. https://doi.org/10.1111/j.1600-0757.1997.tb00110.x.

[8] Baehni PC, Takeuchi Y. Anti-plaque agents in the prevention of biofilm-associated oral diseases. Oral Diseases 2003; 9(Suppl. 1): 23-29.https://doi.org/10.1034/j.1601-0825.9.s1.5.x.

[9] Scheie AA. Modes of action of currently known chemical antiplaque agents other than chlorhexidine. Journal of Dental Research 1989; 68:1609-16.

[10] White DJ, Barker ML, Klukowska M. In vivo antiplaque efficacy of combined antimicrobial dentifrice and rinse hygiene regimens. American Journal of Dentistry 2008; 21:189-96.

[11] Fine DH, Markowitz K, Furgang D, Goldsmith D, Charles CH, Lisante TA, et al. Effect of an essential oil-containing antimicrobial mouthrinse on specific plaque bacteria in vivo. Journal of Clinical Periodontology 2007; 34:652-7.https://doi.org/10.1111/j.1600051X.2007.01096.x.

[12] Balenseifen JW, Madonia JV. Study of dental plaque in orthodontic patients. Journal of Dental Research 1970; 49:320-4. https://doi.org/10.1177/00220345700490022101.

[13] Kocak MM, Ozcan S, Kocak S, Topuz O, Erten H. Comparison of the efficacy of three different mouthrinse solutions in decreasing the level of Streptococcus mutansin saliva. European Journal of Dentistry 2009; 3:57-61.

[14] Wigger-Alberti W, Gysen K, Axmann EM, Wilhelm KP. Efficacy of a new mouthrinse formulation on the reduction of oral malodourin vivo. A randomized, double-blind, placebo-controlled, 3 week clinical study. Journal of Breath Research 2010; 4:017102. https://doi.org/10.1088/1752-7155/4/1/017102.

[15] Moran J, Addy M, Kohut B, Hovliaras CA, Newcombe RG. Efficacy of mouthrinses in inhibiting the development of supragingival plaque over a 4-day period of no oral hygiene. Journal of Periodontology 1994; 65:904-7 .https://doi.org/10.1902/jop.1994.65.10.904

[16] H. R. Chitme, R. Chandra, and S. Kaushik, "Studies on antidiarrheal activity of calotropisgigantea R. Br. in Experimental animals," Journal of Pharmacy \& Pharmaceutical Science 2003; 7: 70-75. 
[17] Narayan A, Mendon C.Comparing the effect of different mouthrinses on de nevo plaque formation. Journal of Contemporary Dental Practice 2012; 13(4): 460-463. https://doi.org/10.5005/jp-journals-10024-1169.

[18] Jagdish L, Anand VK, Kaviyarasan V. Effect of triphala on dental biofilm. Indian Journal of Science and Technology 2009; 2(1):3033.

[19] Versteeg PA, NAM Rosema, Hoenderdos NL, Slot DE, Van der Weijden GA The plaque inhibitory effect of a CPC mouthrinse in a 3-day plaque accumulation model - a cross-over study International Journal of Dental Hygiene 2010;8:269-275. https://doi.org/10.1111/j.1601-5037.2009.00421.x.

[20] Rodrigues IS, de Oliveira DB, de Menezes PC, da Costa FN, Carlos MX, Pereira SL Effect of Lippiasidoides in mouthrinses on de novo plaque formation: a double-blind clinical study in humans. Indian Journal of dental Research 2013; Sep-Oct; 24(5):533-6. https://doi.org/10.4103/0970-9290.123360.

[21] Ulkur F, Arun T, Ozdemir F The effects of three different mouth rinses in a 4-day supragingival plaque regrowth study.EuropeanJournal of Dentistry 2013; Jul;7(3):352-8. https://doi.org/10.4103/1305-7456.115420.

[22] Rivera S, Yévenes I, Reyes J, Norero H. Comparative effect again mouthrinses-gel of chlorexidinewithcommercial mouthrinses in the growth of plaque in 24 hours. Av Periodoncia 2006; 18:163-9.

[23] Claydon N, Addy M. The use of plaque area and plaque index to measure the effect of fluoride and chlorhexidine toothpastes on 24$\mathrm{h}$ plaque regrowth. Journal of Clinical Periodontology 1995; 22:540-2.https://doi.org/10.1111/j.1600-051X.1995.tb00802.x.

[24] Sherp HW. Dental caries. Prospects for prevention. Science 1971; 173:1199-1205.https://doi.org/10.1126/science.173.4003.1199.

[25] Glavind L. Effect of monthly professional mechanical tooth cleaning on periodontal health in adults. Journal of Clinical Periodontology1977; 4: 100-06 https://doi.org/10.1111/j.1600-051X.1977.tb01889.x.

[26] Laher A and Cleaton-Jones PE. Chlorhexidine rinsing in physically handicapped puoils in Katlehong. Journal of the Dental Association of South Africa 1996; 51: 343-46.

[27] Heasman PA and Seymour SS. Pharmacological control of periodontal diseas (1). Antiplaque agents. Journal of Dentistry 1995; 22: 323-26.https://doi.org/10.1016/0300-5712(94)90083-3.

[28] Van Strydonck DA, Slot DE, Van der Velden U, Van der WeijdenF.Effect of a chlorhexidine mouthrinse on plaque, gingival inflammation and staining in gingivitis patients: a systematic review. Journal of Clinical Periodontology 2012 Nov; 39(11):104255. Epub 2012 Sep 7. https://doi.org/10.1111/j.1600-051X.2012.01883.x.

[29] RupaliKalsi, K. L. Vandana, and ShobhaPrakash. Effect of loca drug delivery in chronic periodontitis patients: A metaanalysis. Journal of Indian Society of Periodontology 2011; 15(4): 304 309.https://doi.org/10.4103/0972-124X.92559.

[30] Fardal O, Turnbull RS (1986). A review of the literature on use of chlorhexidine in dentistry. Journal of the American Dental Association. 112: 863-869.https://doi.org/10.14219/jada.archive.1986.0118.

[31] Lang NP, Catalanotto F A, Antezak A A. Quality specific taste impairement following the application of Digluconate mouthrinses. Journal of clinical Periodontology 1988; 15: 43-48. https://doi.org/10.1111/j.1600-051X.1988.tb01553.x.

[32] Kaim JM, Gultz J, Do L and Scherer W. An in vitro investigation of the antimicrobial activity of an herbal mouthrinse. Journal of Clinical Dentistry(1998) 9: 46-48.

[33] Malhotra R, et al. Comparison of the effectiveness of a commercially available herbal mouthrinse with chlorhexidine gluconate at the clinical and patient level. Journal of Indian Society of Periodontology 2011; 15(4):349-52.https://doi.org/10.4103/0972-124X.92567.

[34] Masoumeh K, et al. Comparison of the antimicrobial effects of persica mouthwash and $0.2 \%$ chlorhexidine on aggregatibacterActinomycetemcomitans of healthy individuals and patients with chronic periodontitis. Research Journal of Medical Science 2012; 6(1):18-21.https://doi.org/10.3923/rjmsci.2012.18.21.

[35] Singh A, Daing A, Dixit J. The effect of herbal, essential oil and chlorhexidine mouthrinse on de novo plaque formation. International Journal of Dental Hygiene 2012; 11(1) 48-52. https://doi.org/10.1111/j.1601-5037.2012.00556.x. 